\title{
Evaluation of a combinatorial approach to prion inactivation using an oxidizing agent, SDS, and proteinase $\mathrm{K}$
}

\author{
Jodi D Smith ${ }^{1,2}$, Eric M Nicholson ${ }^{1}$ and Justin J Greenlee ${ }^{1 *}$
}

\begin{abstract}
Background: Prions demonstrate an unusual resistance to methods effective at inactivating conventional microorganisms. This has resulted in a very tangible and difficult infection control challenge to the medical and veterinary communities, as well as animal agriculture and related industries. Currently accepted practices of harsh chemical treatments such as prolonged exposure to sodium hydroxide or sodium hypochlorite, or autoclaving are not suitable in many situations. Less caustic and more readily applicable treatments to contaminated environments are therefore desirable. We recently demonstrated that exposure of the RML scrapie agent to a commercial product containing sodium percarbonate (SPC-P) with or without sodium dodecyl sulfate (SDS) rendered PrP ${ }^{\mathrm{SC}}$ sensitive to proteinase K (PK), but did not eliminate infectivity. The current study was designed to evaluate the efficacy of a combinatorial approach to inactivating prions by exposing RML-positive brain homogenate to SPC-P and SDS followed by PK. Treated samples were evaluated for PrPSC-immunoreactivity by western blot, and residual infectivity by mouse bioassay.

Results: Treatment of infected brain homogenate with SPC-P and SDS followed by PK exposure resulted in a 4-5 $\log _{10}$ reduction in infectivity when bioassayed in tga20 mice.

Conclusions: This study demonstrates that exposure of the RML scrapie agent to SPC-P and SDS followed by PK markedly reduces, but does not eliminate infectivity. The results of this study encourage further investigation into whether consecutive or concomitant exposure to sodium percarbonate, SDS, and a protease may serve as a viable and non-caustic option for prion inactivation.
\end{abstract}

Keywords: Inactivation, Prion, Proteinase, Scrapie, Sodium dodecyl sulfate, Sodium percarbonate

\section{Background}

Prions are the causative agent of the transmissible spongiform encephalopathies (TSE) and consist predominantly, if not solely, of an abnormally folded, partially protease resistant isoform of the cellular prion protein (termed $\mathrm{PrP}^{\mathrm{Sc}}$ ) [1]. However, the exact nature of the infectious agent remains open to debate with the identification of protease sensitive forms of disease-associated PrP [2-4] and retention of infectivity after complete $\operatorname{PrP}$ digestion [5]. Regardless of their specific identity, prions are notoriously difficult to inactivate, withstanding methods effective against conventional pathogens, such as moderate heating,

\footnotetext{
* Correspondence: justin.greenlee@ars.usda.gov

${ }^{1}$ Virus and Prion Research Unit, National Animal Disease Center, USDA,

Agricultural Research Service, 1920 Dayton Ave, Ames, IA 50010, USA

Full list of author information is available at the end of the article
}

ultraviolet irradiation, and formalin exposure [6]. Prions are transmitted more efficiently within a species, but interspecies transmission is also possible - the most infamous example being transmission of bovine spongiform encephalopathy (BSE) to humans resulting in the variant form of Creutzfeldt-Jakob disease (vCJD) [7-9]. Because BSE poses a lethal zoonotic disease risk, effective prion decontamination methods that can be applied on a large scale, such as in abattoirs, are desirable to further minimize the risk of zoonotic transmission. Efficacious decontamination procedures that can be applied to environmental settings are also desirable to aid in the control of other TSEs of veterinary and public health importance such as scrapie and chronic wasting disease, which are horizontally transmitted $[10,11]$. Ideally, effective methods would be nonhazardous to personnel applying them on a large scale

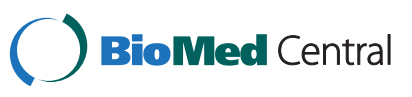


and reasonably sensitive to ecological systems when applied to contaminated outdoor environments.

Current decontamination recommendations by the World Health Organization, depending on material to be sterilized, include autoclaving at $134^{\circ} \mathrm{C}$ for up to 1 hour, or prolonged exposure to $1 \mathrm{~N}$ sodium hydroxide or $\geq 20,000 \mathrm{ppm}$ sodium hypochlorite [12]. The most recent edition of the US Department of Health and Human Service's Biosafety in Microbiological and Biomedical Laboratories also recognizes the phenolic disinfectant Environ LpH (Steris Corp.) as an acceptable decontaminating solution for surfaces and reusable instruments [13]. Inactivation treatments with sodium hydroxide or sodium hypochlorite are especially detrimental to delicate surgical and diagnostic equipment, spurring research into less caustic alternatives. Recent lines of investigation have included treatment of contaminated material with sodium dodecyl sulfate (SDS), proteolytic enzymes, or peroxygen compounds with variable success. Sodium dodecyl sulfate has long been known to affect prion infectivity, but its effectiveness varies with the prion strain to which it is applied. Prior investigations have demonstrated minimal effects on CJD infectivity [14], but up to a $3 \log _{10}$ reduction on scrapie infectivity [15]. More recently, SDS in combination with $\mathrm{NaOH}$ has been shown to successfully inactivate the $263 \mathrm{~K}$ hamster scrapie agent, resulting in a $>5.5 \log _{10}$ reduction in infectivity [16,17]. Proteases have also been reported to have prion inactivation potential [18-22]. Broad spectrum proteases, such as proteinase $\mathrm{K}$ (PK) [18] and pronase [19], have been shown to substantially reduce infectivity after prolonged exposure times. More recently, a genetically engineered variant of subtilisin applied under alkaline conditions was shown to reduce infectivity of a mouse-adapted BSE strain by $>7$ logs [21]. While these reagents have demonstrated anti-prion activity on their own, combining proteases and SDS appears to enhance their prion inactivating abilities. In two independent studies, pronase [19] or pronase and PK [23] in combination with SDS resulted in greater reductions in infectivity versus protease(s) alone. Peroxygens, such as liquid hydrogen peroxide [24-26] and peracetic acid [27], have been shown to promote limited inactivation. However, more recent studies have demonstrated significant reductions in infectivity for hamster-adapted scrapie and mouse-adapted BSE strains using vaporized hydrogen peroxide $[25,28]$.

Sodium percarbonate is an oxidizing agent composed of sodium carbonate and hydrogen peroxide $\left(2 \mathrm{Na}_{2} \mathrm{CO}_{3}\right.$. $3 \mathrm{H}_{2} \mathrm{O}_{2}$ ). It has a high degree of environmental compatibility, with degradation products consisting of water, oxygen, and sodium carbonate, and generates a $\mathrm{pH}$ of 10-11 in aqueous solution. Until recently, its efficacy with regard to prion inactivation had not been reported. In a prior study [29], we found that exposure of RML-positive brain homogenate to a sodium percarbonate-containing product (SPC-P) with or without SDS was unsuccessful at eliminating infectivity, but did increase sensitivity of $\mathrm{PrP}^{\mathrm{Sc}}$ to $\mathrm{PK}$ digestion. The current study builds upon those results, examining a combinatorial approach to inactivating prions by exposing infected material to SPC-P and SDS followed by treatment with $\mathrm{PK}$. Brain homogenate from terminally ill C57BL/6 mice positive for the mouse-adapted RML strain of scrapie was treated with a combination of SPC-P and $2.5 \% \mathrm{w} / \mathrm{v}$ SDS for 30 minutes at room temperature followed by exposure to PK. Western blot (WB) analysis was used to detect residual $\operatorname{PrP}^{\mathrm{Sc}}$ in treated samples, and residual infectivity was assayed by intracranial inoculation into prion protein overexpressing tga 20 mice [30].

\section{Results}

\section{Immunoblotting}

Residual $\operatorname{PrP}^{\mathrm{Sc}}$ in brain homogenate treated with a low or high concentration of the SPC-containing product (SPC- $\mathrm{P}_{\mathrm{L}}$ and $\mathrm{SPC}-\mathrm{P}_{\mathrm{H}}$, respectively) in combination with $2.5 \% \mathrm{w} / \mathrm{v}$ SDS followed by exposure to PK was assayed via western blot (WB). Immunoblots were performed in triplicate with representative blots presented in Figure 1. Immunoreactivity for the di-, mono-, and unglycosylated forms of $\mathrm{PrP}^{\mathrm{Sc}}$ was faintly detectable in samples exposed to SPC-P $\mathrm{L}_{\mathrm{L}}$ alone followed by PK (Figure 1, lane 3). Immunoreactivity was undetectable in samples treated with SPC- $\mathrm{P}_{\mathrm{H}}$ alone followed by PK exposure, or either concentration of SPC-P combined with SDS and followed by PK (Figure 1, lanes 4-6). Control samples exposed to SDS alone, PK alone, or SDS followed by PK retained PrP-immunoreactivity (Figure 1A and B, lanes 7-9).

\section{Mouse bioassay}

Residual infectivity in treated samples was assayed via intracranial inoculation of tga 20 mice. The average number of days to terminal disease for the positive control group (untreated RML-positive brain homogenate) was $65.5 \pm 3.4$ days, which is typical of RML disease kinetics in tga 20 mice inoculated intracranially [30]. As previously reported [29], ten-fold serial dilutions of this stock resulted in increased mean incubation times and survival percentages (Table 1). The survival curves generated from these data were used as the comparative standard when evaluating survival time in mice inoculated with treated samples and for approximating reductions in infectivity. Consistent clinical signs observed in scrapieaffected mice included ataxia that progressed to a listing or rolling gait in some cases, pelvic limb paresis, and lethargy. All but 2 animals in the negative control group (treated RML-negative brain homogenate) survived until study termination. One mouse was euthanized due to severe hydrocephalus and the cause of death of the other mouse was undetermined. 


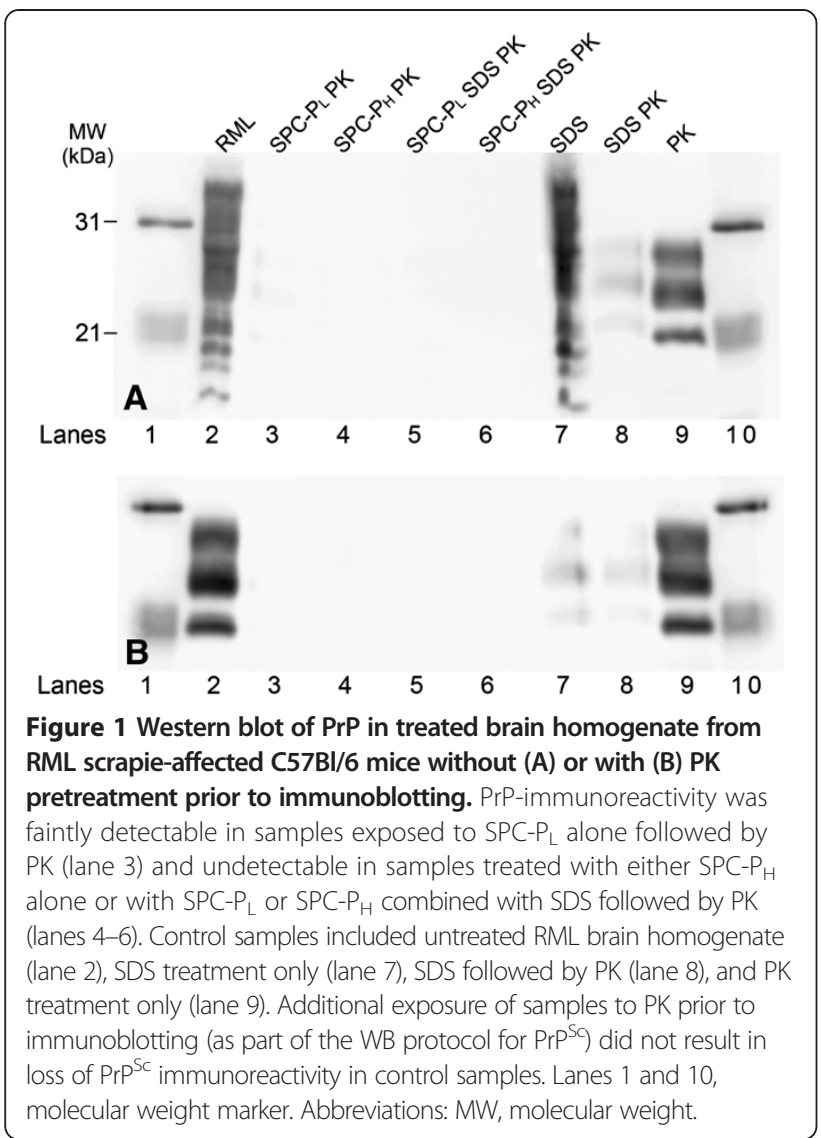

Mice inoculated with samples exposed to $\mathrm{SPC}-\mathrm{P}_{\mathrm{L}}$ or SDS- $\mathrm{P}_{\mathrm{H}}$ alone followed by $\mathrm{PK}$ had mean incubation times of $107 \pm 39$ and $98 \pm 16.8$ days, respectively, corresponding to an approximate $2-3 \log _{10}$ reduction in infectivity (Figure 2). Two of 19 mice (11\%) in the SPC- $\mathrm{P}_{\mathrm{L}}$ group survived until study termination, while all mice in the SDS- $\mathrm{P}_{\mathrm{H}}$ group were euthanized due to severe clinical signs of scrapie. Exposure to the combination of SPC-P and SDS followed by PK resulted in a $4-5 \log _{10}$ reduction in infectivity (Figure 2). The mean incubation time for this combination using SPC- $\mathrm{P}_{\mathrm{L}}$ was $431 \pm 72.4$ days, with $73 \%$ of mice surviving until study termination. Two mice from this group were censored from survival statistics due to intercurrent disease. For the combination using SPC- $\mathrm{P}_{\mathrm{H}}$, only 1 mouse developed clinical signs at 108 days post-inoculation and was definitively diagnosed with scrapie (88\% survival). Four mice in this group died within 7 days of inoculation due to complications from the procedure, and 4 additional mice were later censored due to intercurrent disease. Mice inoculated with samples exposed to PK alone had an average incubation time of $62 \pm 5.2$ days with $0 \%$ survival. Mice inoculated with samples exposed to SDS alone followed by PK had a mean incubation time of $86 \pm 7.1$ days,
Table 1 Average incubation times and survival percentages of tga20 mice inoculated intracranially with serially diluted or treated RML scrapie brain homogenate

\begin{tabular}{|c|c|c|}
\hline Group & Dilution or treatment & $\begin{array}{l}\text { Mean incubation time } \\
\text { in days } \pm \text { SD (\% survival) }\end{array}$ \\
\hline & \multicolumn{2}{|l|}{ RML titration series ${ }^{*}$} \\
\hline & $10^{0}$ & $66 \pm 3.4(0 \%)$ \\
\hline & $10^{-1}$ & $74 \pm 3.3(0 \%)$ \\
\hline & $10^{-2}$ & $83 \pm 6.1(0 \%)$ \\
\hline & $10^{-3}$ & $128 \pm 29.1(22 \%)$ \\
\hline & $10^{-4}$ & $184 \pm 39.6(78 \%)$ \\
\hline & $10^{-5}$ through $10^{-12}$ & N/A (100\%) - study termination \\
\hline & \multicolumn{2}{|l|}{ Treated $R M L$} \\
\hline & $S P C-P_{L}^{*}$ & $67 \pm 2.6(0 \%)$ \\
\hline & $S P C-P_{H}^{*}$ & $70 \pm 6.0(0 \%)$ \\
\hline & $S P C-P_{L}+S D S^{*}$ & $93 \pm 9.7(0 \%)$ \\
\hline & $\mathrm{SPC}-\mathrm{P}_{\mathrm{H}}+\mathrm{SDS}^{*}$ & $93 \pm 7.6(0 \%)$ \\
\hline 1 & $S P C-P_{L} \Pi P K$ & $107 \pm 39.0(11 \%)$ \\
\hline 2 & SPC-P $\mathrm{P}_{H} \Pi \mathrm{PK}$ & $98 \pm 16.8(0 \%)$ \\
\hline 3 & $\mathrm{SPC}-\mathrm{P}_{\mathrm{L}}+\mathrm{SDS} \Pi \mathrm{PK}$ & $431 \pm 72.4(73 \%)$ \\
\hline 4 & $\mathrm{SPC}-\mathrm{P}_{\mathrm{H}}+\mathrm{SDS} \Pi \mathrm{PK}$ & $108^{\wedge}(88 \%)$ \\
\hline 5 & SDS control & $85 \pm 12.3(0 \%)$ \\
\hline 6 & PK control & $62 \pm 5.2(0 \%)$ \\
\hline 7 & SDS П PK control & $86 \pm 7.1(0 \%)$ \\
\hline
\end{tabular}

*Smith et al. [29]; ^only 1 mouse in this group was euthanized due to clinical scrapie.

SD standard deviation.

corresponding to an approximate $2 \log _{10}$ reduction in infectivity but $0 \%$ survival.

\section{Discussion}

Oxidizing agents have been used with variable success in prion inactivation studies. Recent studies applying vaporized hydrogen peroxide (VHP) to prion-contaminated stainless steel surfaces have demonstrated significant reductions in infectivity for hamster-adapted scrapie and mouse-adapted BSE strains [25,28]. A 4.5-5.6 $\log _{10}$ reduction in infectivity of the hamster-adapted $263 \mathrm{~K}$ scrapie agent was demonstrated after treatment of contaminated steel wires with VHP alone or in combination with an enzymatic cleaner [28]. Similarly, exposure of wires contaminated with the mouse-adapted 6 PB1 strain of BSE to VHP alone resulted in a reduction of $>5.5 \operatorname{logs}$ [25]. In contrast, a $\leq 1 \log _{10}$ reduction in infectivity was demonstrated with liquid hydrogen peroxide [25]. Our prior work examining SPC-P treatment alone also demonstrated little to no $\left(\leq 1 \log _{10}\right)$ reduction in infectivity of the RML scrapie agent [29]. While VHP has demonstrated greater efficacy against prions, we felt the efficacy of liquid hydrogen peroxide might be improved in combination with other protein-disrupting conditions and compounds, 


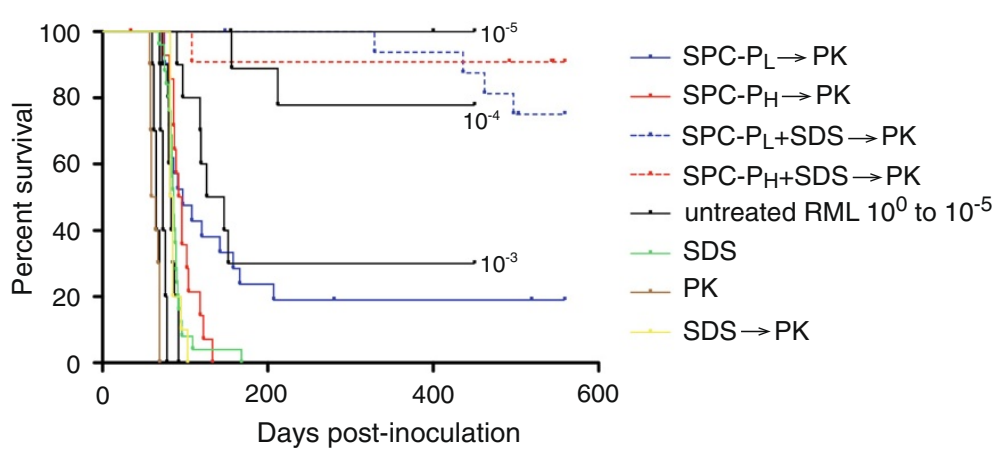

Figure 2 Effect of various treatment conditions on scrapie infectivity in tga20 mice. Kaplan-Meier survival curves were generated to compare treatment conditions to 10-fold serial dilutions of RML scrapie in tga20 mice. Treatment with PK alone had no effect on infectivity. Treatment with SDS alone or SDS followed by PK (SDS $\rightarrow$ PK) yielded an approximate $2 \log _{10}$ reduction in infectivity with $0 \%$ survival. Similarly, treatment with either SPC- $P_{L}$ or SPC- $P_{H}$ alone followed by exposure to PK resulted in a $2-3 \log _{10}$ reduction in infectivity. The combination of SPC- $P_{L}$ or SPC- $P_{H}$ with SDS followed by PK resulted in a $4-5 \log _{10}$ reduction in infectivity with $73 \%$ and $88 \%$ survival, respectively. Abbreviations: SPC- $\mathrm{P}_{\mathrm{L}}$ or ${ }_{\mathrm{H}}$, low or high concentration sodium percarbonate-based product; SDS, sodium dodecyl sulfate; PK, proteinase $\mathrm{K}$.

such as the alkaline conditions attained with SPC solution and the denaturing and proteolytic effects of SDS and PK, respectively.

In this report, we investigated the viability of combining sodium percarbonate, SDS, and PK to inactivate the RML scrapie agent. Treated samples were evaluated for $\mathrm{PrP}^{\mathrm{Sc}}$ immunoreactivity by WB and residual infectivity by mouse bioassay. Product choice and treatment conditions for this study were defined based on our aforementioned study in which we demonstrated exposure of the RML scrapie agent to SPC-P with or without SDS increased the sensitivity of $\mathrm{PrP}^{\mathrm{Sc}}$ to $\mathrm{PK}$, but did not eliminate infectivity. The results of the current study demonstrating loss of $\operatorname{PrP}^{\mathrm{Sc}}$ immunoreactivity after treatment with SPC$\mathrm{P}_{\mathrm{H}}$ alone, or either concentration of SPC-P combined with SDS, followed by PK are in agreement with previous findings. Exposure of brain homogenate to this combination resulted in a $>4 \log _{10}$ reduction in infectivity, with $73 \%$ of challenged mice from the SPC- $\mathrm{P}_{\mathrm{L}}+\mathrm{SDS} \rightarrow \mathrm{PK}$ group and $88 \%$ of mice from the SPC- $\mathrm{P}_{\mathrm{H}}+\mathrm{SDS} \rightarrow$ PK group surviving until study termination. Treatment with $\mathrm{PK}$ alone had no effect on infectivity, while treatment with SDS alone or $\mathrm{SDS} \rightarrow \mathrm{PK}$ resulted in an approximate $2 \log _{10}$ reduction, but $0 \%$ survival. Treatment with either SPC- $\mathrm{P}_{\mathrm{L}}$ or $\mathrm{SPC}-\mathrm{P}_{\mathrm{H}}$ alone followed by $\mathrm{PK}$ also had a modest impact on infectivity resulting in a $2-3 \log _{10}$ reduction in infectivity, but with $11 \%$ and $0 \%$ survival, respectively. In our previous study we reported that SPC- $\mathrm{P}_{\mathrm{L}}$ or SPC- $\mathrm{P}_{\mathrm{H}}$ alone had little to no effect on infectivity $\left(\leq 1 \log _{10}\right)$, but in combination with SDS resulted in a $2-3 \log _{10}$ reduction in infectivity but with few survivors. Taken together, these data indicate the most viable approach is utilizing all components in combination.

Both concentrations of SPC-P used in this study generated a $\mathrm{pH}$ of approximately 11 in solution. We previously evaluated the effect of $\mathrm{pH}$ on this particular inoculum and demonstrated loss of $\operatorname{PrP}^{\mathrm{Sc}}$ immunoreactivity after incubation of brain samples buffered with $0.35 \mathrm{M} \mathrm{Na}_{2} \mathrm{HPO}_{4}$ ( $\mathrm{pH}$ 11.0). It is well established that prion infectivity is reduced under extremely basic conditions, such as exposure to $\mathrm{NaOH}(\mathrm{pH} 12-14)$ [31-33]. While the $\mathrm{pH}$ generated by SPC-P is lower at near 11, it appears to be a favorable characteristic of the compound with regard to $\mathrm{PrP}^{\mathrm{Sc}}$ protease sensitivity and is likely contributing to the mechanism of infectivity reduction observed in this study. Also, although treatment with this combination rendered $\operatorname{PrP}^{\mathrm{Sc}}$ sensitive to $\mathrm{PK}$ and substantially decreased infectivity, it did not completely eliminate infectivity. This was not unexpected, as a number of studies have demonstrated dissociation of $\mathrm{PrP}^{\mathrm{Sc}}$ and infectivity $[2,5,34,35]$. Our results support the conclusion that biochemical analysis alone is insufficient for determination of prion infectivity. The observed $\mathrm{PrP}^{\mathrm{Sc}}$ /infectivity mismatch warrants a number of considerations including WB sensitivity, epitope disruption by inactivation treatments, and alternative infectious agents to solely $\operatorname{PrP}^{\mathrm{Sc}}$. It is possible the amount of residual $\mathrm{PrP}^{\mathrm{Sc}}$ in our treated samples was below the detection limit of our WB, or it may be that a true dissociation of $\operatorname{PrP}^{\mathrm{Sc}}$ and TSE infectivity exists supporting the actuality of alternative infectious agents to $\operatorname{PrP}^{\mathrm{Sc}}$ [36]. A recent study has demonstrated poor correlation between infectivity and WB results for sheep scrapie and sheep BSE [35], in line with observations that PK-sensitive PrP particles are associated with disease [2,37].

\section{Conclusions}

This study is the first to report the efficacy of a novel combination of oxidizing agent, detergent, and protease to inactivate prions. Exposure of the RML scrapie agent to an SPC-containing product combined with SDS followed by PK exposure substantially reduced prion 
infectivity by $4-5$ logs. While this combination did not completely eliminate infectivity, it is feasible that further investigation and protocol modification may result in improved efficacy yielding a non-hazardous and widely applicable solution for prion decontamination.

\section{Methods \\ Inactivation of inoculum}

Brain samples from negative control or RML-positive mice were prepared as $10 \% \mathrm{w} / \mathrm{v}$ brain homogenates in phosphate buffered saline as described previously [29]. Homogenates were diluted to a concentration of $5 \%$ in either a $2.1 \%\left(\mathrm{SPC}-\mathrm{P}_{\mathrm{L}}, \mathrm{pH} 10.7\right)$ or $21.0 \%\left(\mathrm{SPC}-\mathrm{P}_{\mathrm{H}}\right.$, $\mathrm{pH}$ 10.6) solution of a commercial product containing SPC (OxiMagic ${ }^{\mathrm{Tn}}$, Clorox Company; 50-60\% SPC) with or without $2.5 \%$ sodium dodecyl sulfate (SDS). Manufacturer's instructions on concentration were followed ( $2.1 \%$ working solution), but additional parameters were experimentally defined. Samples were agitated under ambient oxygen in microcentrifuge tubes at $25^{\circ} \mathrm{C}$ for 30 min. Next, proteinase K (PK) (USB Corporation) was added to a final concentration of $0.08 \mathrm{mg} / \mathrm{mL}$ and samples were incubated at $48^{\circ} \mathrm{C}$ for $40 \mathrm{~min}$. Pefabloc (Roche) was added to a final concentration of $1 \mathrm{mg} / \mathrm{mL}$ to quench PK activity. Samples were then diluted with sterile saline to a final concentration of $1 \%$ for inoculation (final $\mathrm{pH}$ values of 10.3 and 10.6 for $\mathrm{SPC}_{\mathrm{L}} \mathrm{P}_{\mathrm{L}}$ and SPC- $\mathrm{P}_{\mathrm{H}}$-treated samples, respectively). Samples were inoculated intracranially (see below) into 10-20 tga20 mice per treatment condition. Mice $(n=10 /$ group) inoculated with RML-positive brain homogenate exposed to $0.08 \mathrm{mg} / \mathrm{mL}$ PK alone at $48^{\circ} \mathrm{C}$ for $40 \mathrm{~min}$, or $2.5 \% \mathrm{w} / \mathrm{v}$ SDS alone or followed by PK (as above) were included as PK-only, SDS-only, and SDS PK controls, respectively. Mice ( $\mathrm{n}=10$ /group) inoculated with RML-negative brain homogenate treated with SPC-P with or without SDS served as negative controls. Samples were stored at $-20^{\circ} \mathrm{C}$ until thawing for western blot analysis and inoculation into tga20 mice. Mice were inoculated (see below) within 12-24 hours of sample treatment.

\section{Western blotting}

Treated samples from each inactivation condition along with controls were examined for $\operatorname{PrP}^{\mathrm{Sc}}$ via western blot. Pretreatment of brain homogenate with PK was performed on one set of blots and omitted on repeated blotting of the same samples. Briefly, samples were digested with PK using a final concentration of $0.08 \mathrm{mg} / \mathrm{mL}$ of at $48^{\circ} \mathrm{C}$ for $40 \mathrm{~min}$. Pefabloc was added to a final concentration of $0.1 \mathrm{mg} / \mathrm{mL}$ to quench PK activity. Samples were dissolved in SDS-PAGE sample buffer and analyzed by standard western blotting procedures. A tissue equivalent of $1.0 \mathrm{mg}$ was loaded onto the gel for each sample. $\operatorname{PrP}^{\mathrm{Sc}}$ was detected using monoclonal antibody 6H4 (Prionics, La Vista, NE) at a 1:10,000 $(0.1 \mu \mathrm{g} / \mathrm{mL})$ dilution applied for $1 \mathrm{hr}$ at room temperature or $4^{\circ} \mathrm{C}$ overnight. A biotinylated sheep anti-mouse secondary antibody and a streptavidin-horseradish peroxidase (HRP) conjugate (GE Healthcare, Pittsburgh, PA) were used in conjunction with the ECL Plus detection kit (GE Healthcare) to detect immunolabeling. Secondary antibody and streptavidin-HRP conjugate incubations were conducted at room temperature for 1 hour. Blots were developed using the Typhoon 9410 Variable Mode Imager (Molecular Dynamics, Sunnyvale, CA).

\section{Mouse bioassay}

Comparative survival curves were generated as previously described [29] in mice of the B6;129S7-Prnp ${ }^{\text {tm1Cwe }} \mathrm{Tg}$ (Prnp)a20Cwe/CweCnrm (tga20) line [30]. For all inoculations, tga 20 mice were anesthetized with isoflurane and a 30 gauge tuberculin syringe was used to inject 20 microliters of brain homogenate into the right cerebral hemisphere at a depth of 3-5 mm. Mice were monitored for 48 hours post-inoculation for procedure-related adverse events. Mice were then monitored daily and euthanized when they displayed unequivocal neurological signs, or at the time of study termination (560 days post-inoculation). Scrapie diagnosis was confirmed with a combination of WB, histopathology, and immunohistochemistry for PrP. Experimental and control groups included mice inoculated with RML brain homogenate treated as follows: 1 ) SPC- $\mathrm{P}_{\mathrm{L}}$ followed by PK, 2) SPC- $\mathrm{P}_{\mathrm{H}}$ followed by PK, 3) SPC- $\mathrm{P}_{\mathrm{L}}+\mathrm{SDS}$ followed by PK, 4) SPC-P + SDS followed by $\mathrm{PK}, 5) \mathrm{SDS}$ only at $\left.25^{\circ} \mathrm{C} \times 30 \mathrm{~min}, 6\right) \mathrm{PK}$ only at $48^{\circ} \mathrm{C}$ for $\left.40 \mathrm{~min}, 7\right)$ SDS followed by PK (Table 1). This experiment was carried out in accordance with the Guide for the Care and Use of Laboratory Animals (Institute of Laboratory Animal Resources, National Academy of Sciences, Washington, DC) and was approved by the National Animal Disease Center's Animal Care and Use Committee (protocol \#2422).

\section{Statistics}

Kaplan-Meier survival curves were generated using statistical software (Prism version 4.0, GraphPad Software). To estimate reductions in infectivity, survival curves from treated groups were compared to those of the titration study using the logrank test with a level of statistical significance of 0.05 . Mice that died within the first 21 days PI due to complications related to intracranial inoculation or were removed from the study for humane reasons (e.g. intercurrent disease, injuries) prior to developing clinical signs were censored and not included in survival analyses.

\section{Abbreviations}

BSE: Bovine spongiform encephalopathy; CJD: Creutzfeldt-Jakob disease; MW: Molecular weight; PI: Post-inoculation; PK: Proteinase K; PrP ${ }^{\mathrm{Sc}}$ : Disease- 
associated isoform of the prion protein; RML: Rocky Mountain Laboratory strain of the scrapie agent; SDS: Sodium dodecyl sulfate; SPC-P: Sodium percarbonate-based product; SPC-P: Low concentration SPC-P; SPC-PH: High concentration SPC-P; TSE: Transmissible spongiform encephalopathy; WB: Western blot.

\section{Competing interests}

The authors declare that they have no competing interests.

\section{Authors' contributions}

JDS conceived of the study, carried out the western blot and animal bioassay studies, and drafted the manuscript. EMN participated in the design of the study and interpretation of results. JJG participated in the design of the study and helped to draft the manuscript. All authors read and approved the final manuscript.

\section{Authors' information}

JDS and JJG are Research Veterinary Medical Officers in the NADC VPRU. JDS is a Postdoctoral Research Associate. EMN is a Research Chemist and Lead Scientist in the VPRU.

\section{Acknowledgments}

The authors thank K. Hassall, T. Tatum, L. Mandell, M. Church, and D. Panthen for excellent technical assistance. Mention of trade names or commercial products in this report is solely for the purpose of providing specific information and does not imply recommendation or endorsement by the U.S. Department of Agriculture. USDA is an equal opportunity provider and employer

\section{Author details}

1 Virus and Prion Research Unit, National Animal Disease Center, USDA Agricultural Research Service, 1920 Dayton Ave, Ames, IA 50010, USA. ${ }^{2}$ Department of Veterinary Pathology, College of Veterinary Medicine, lowa State University, Ames, IA 50011, USA.

Received: 27 February 2013 Accepted: 24 July 2013

Published: 25 July 2013

\section{References}

1. Prusiner SB: Prions. Proc Nat Acad Sci USA 1998, 95(23):13363-13383.

2. Gambetti $P$, Dong Z, Yuan J, Xiao X, Zheng M, Alshekhlee A, Castellani R, Cohen M, Barria MA, Gonzalez-Romero D, Belay ED, Schonberger LB, Marder K, Harris C, Burke JR, Montine T, Wisniewski T, Dickson DW, Soto C, Hulette CM, Mastrianni JA, Kong Q, Zou WQ: A novel human disease with abnormal prion protein sensitive to protease. Ann Neurol 2008 63(6):697-708

3. Colby D, Prusiner SB: Prions. Cold Spring Harb Perspect Biol 2011, 3: epub a006833.

4. Cronier SGN, Tattum MH, Jackson GS, Clarke AR, Colligne J, Wadsworth JDF: Detection and characterization of proteinase K-sensitive disease-related prion protein with thermolysin. Biochem J 2008, 416:297-305.

5. Miyazawa K, Emmerling K, Manuelidis L: High CJD infectivity remains after prion protein is destroyed. J Cell Biochem 2011, 112(12):3630-3637.

6. Taylor DM: Inactivation of transmissible degenerative encephalopathy agents: a review. Vet J 2000, 159(1):10-17

7. Bruce ME, Will RG, Ironside JW, McConnell I, Drummond D, Suttie A, McCardle L, Chree A, Hope J, Birkett C, Cousens S, Fraser H, Bostock CJ: Transmissions to mice indicate that 'new variant' CJD is caused by the BSE agent. Nature 1997, 389(6650):498-501.

8. Collinge J, Sidle KC, Meads J, Ironside J, Hill AF: Molecular analysis of prion strain variation and the aetiology of 'new variant' CJD. Nature 1996, 383(6602):685-690.

9. Wilesmith JW, Wells GA, Cranwell MP, Ryan JB: Bovine spongiform encephalopathy: epidemiological studies. Vet Rec 1988, 123(25):638-644

10. Detwiler LA, Baylis M: The epidemiology of scrapie. Rev Sci Tech 2003 , 22(1):121-143

11. Sigurdson CJ: A prion disease of cervids: chronic wasting disease. Vet Res 2008, 39(4):41.

12. WHO: WHO infection control guidelines for transmissible spongiform encephalopathies. Geneva: WHO/CDS/CSR/APH/20003; 1999:29-32.
13. US Department of Health and Human Services: Biosafety in Microbiological and Biomedical Laboratories. 5th edition. Washington DC: US Government Printing Office; 2007

14. Walker AS, Inderlied CB, Kingsbury DT: Conditions for the chemical and physical inactivation of the K, Fu. strain of the agent of CreutzfeldtJakob disease. Am J Pub Health 1983, 73(6):661-665.

15. Millson GC, Hunter GD, Kimberlin RH: The physico-chemical nature of the scrapie agent. In Slow Virus Diseases of Animals and Man. Volume 44. Edited by Kimberlin RH. Amsterdam: North-Holland; 1976:243-264.

16. Lemmer K, Mielke M, Kratzel C, Joncic M, Oezel M, Pauli G, Beekes M: Decontamination of surgical instruments from prions, II. In vivo findings with a model system for testing the removal of scrapie infectivity from steel surfaces. J Gen Virol 2008, 89(Pt 1):348-358.

17. Beekes $M$, Lemmer $K$, Thomzig A, Joncic M, Tintelnot K, Mielke M: Fast, broad-range disinfection of bacteria, fungi, viruses and prions. J Gen Virol 2010, 91(Pt 2):580-589

18. Prusiner SB, McKinley MP, Groth DF, Bowman KA, Mock NI, Cochran SP, Masiarz FR: Scrapie agent contains a hydrophobic protein. Proc Natl Acad Sci USA 1981, 78(11):6675-6679.

19. Cho HJ: Inactivation of the scrapie agent by pronase. Can J Comp Med 1983, 47(4):494-496.

20. McLeod AH, Murdoch H, Dickinson J, Dennis MJ, Hall GA, Buswell CM, Carr J, Taylor DM, Sutton JM, Raven ND: Proteolytic inactivation of the bovine spongiform encephalopathy agent. Biochem Biophys Res Comm 2004, 317(4):1165-1170.

21. Dickinson J, Murdoch H, Dennis MJ, Hall GA, Bott R, Crabb WD, Penet C, Sutton JM, Raven ND: Decontamination of prion protein (BSE301V) using a genetically engineered protease. J Hosp Infect 2009, 72(1):65-70.

22. Pilon JL, Nash PB, Arver T, Hoglund D, Vercauteren KC: Feasibility of infectious prion digestion using mild conditions and commercial subtilisin. J Virol Methods 2009, 161(1):168-172

23. Jackson GS, McKintosh E, Flechsig E, Prodromidou K, Hirsch P, Linehan J, Brandner S, Clarke AR, Weissmann C, Collinge J: An enzyme-detergent method for effective prion decontamination of surgical steel. J Gen Virol 2005, 86(Pt 3):869-878

24. Brown P, Gibbs CJ Jr, Amyx HL, Kingsbury DT, Rohwer RG, Sulima MP, Gajdusek DC: Chemical disinfection of Creutzfeldt-Jakob disease virus. New Engl J Med 1982, 306(21):1279-1282.

25. Fichet G, Antloga K, Comoy E, Deslys JP, McDonnell G: Prion inactivation using a new gaseous hydrogen peroxide sterilisation process. $J$ Hosp Infect 2007, 67(3):278-286.

26. Brown P, Rohwer RG, Green EM, Gajdusek DC: Effect of chemicals, heat, and histopathologic processing on high-infectivity hamster-adapted scrapie virus. J Infect Dis 1982, 145(5):683-687.

27. Taylor DM: Resistance of the ME7 scrapie agent to peracetic acid. Vet Microbiol 1991, 27(1):19-24

28. Fichet G, Comoy E, Duval C, Antloga K, Dehen C Charbonnier A, McDonnell G, Brown P, Lasmezas Cl, Deslys JP: Novel methods for disinfection of prion-contaminated medical devices, Lancet 2004, 364(9433):521-526.

29. Smith JD, Nicholson EM, Foster GH, Greenlee JJ: Exposure of RML scrapie agent to a sodium percarbonate-based product and sodium dodecyl sulfate renders PrPSc protease sensitive but does not eliminate infectivity. BMC Vet Res 2013: . 10.1186/1746-6148-9-8.

30. Fischer M, Rulicke T, Raeber A, Sailer A, Moser M, Oesch B, Brandner S, Aguzzi A, Weissmann C: Prion protein (PrP) with amino-proximal deletions restoring susceptibility of PrP knockout mice to scrapie. EMBO J 1996, 15(6):1255-1264.

31. Brown P, Rohwer RG, Gajdusek DC: Newer data on the inactivation of scrapie virus or Creutzfeldt-Jakob disease virus in brain tissue. $J$ Infect Dis 1986, 153(6):1145-1148.

32. Taylor DM, Fraser H, McConnell I, Brown DA, Brown KL, Lamza KA, Smith GR: Decontamination studies with the agents of bovine spongiform encephalopathy and scrapie. Arch Virol 1994, 139(3-4):313-326.

33. Unal A, Thyer J, Uren E, Middleton D, Braun M, Maher D: Investigation by bioassay of the efficacy of sodium hydroxide treatment on the inactivation of mouse-adapted scrapie. Biologicals 2007, 35(3):161-164.

34. Bruederle CE, Hnasko RM, Kraemer T, Garcia RA, Haas MJ, Marmer WN, Carter JM: Prion infected meat-and-bone meal is still infectious after biodiesel production. PLoS One 2008, 3(8):e2969.

35. Gonzalez L, Thorne L, Jeffrey M, Martin S, Spiropoulos J, Beck KE, Lockey RW, Vickery CM, Holder T, Terry L: Infectious titres of sheep scrapie and bovine 
spongiform encephalopathy agents cannot be accurately predicted from quantitative laboratory test results. J Gen Virol 2012, 93(Pt 11):2518-2527.

36. Manuelidis L: A $25 \mathrm{~nm}$ virion is the likely cause of transmissible spongiform encephalopathies. J Cell Biochem 2007, 100(4):897-915.

37. Head MW, Knight R, Zeidler M, Yull H, Barlow A, Ironside JW: A case of protease sensitive prionopathy in a patient in the UK. Neuropathol Appl Neurobiol 2009, 35(6):628-632.

doi:10.1186/1746-6148-9-151

Cite this article as: Smith et al.: Evaluation of a combinatorial approach to prion inactivation using an oxidizing agent, SDS, and proteinase $\mathrm{K}$. BMC Veterinary Research 2013 9:151.

\section{Submit your next manuscript to BioMed Central and take full advantage of:}

- Convenient online submission

- Thorough peer review

- No space constraints or color figure charges

- Immediate publication on acceptance

- Inclusion in PubMed, CAS, Scopus and Google Scholar

- Research which is freely available for redistribution 